\title{
COMPARISON OF INCISOR, MOLAR \& LOWER ANTERIOR FACIAL DIVERGENCE IN HYPODIVERGENT, HYPERDIVERGENT AND NORMODIVERGENT PATIENT: A STUDY MODEL AND CEPHALOMETRIC STUDY
}

\author{
Jignesh Keshubhai Kakadiya ${ }^{1}$, Prabhuraj Kambalyal', Mukesh Singla ${ }^{3}$, Jyoti Jingar ${ }^{4}$, Pradeep Vishnoi ${ }^{5}$ \\ ${ }^{1,3,4,5}$ Post Graduate,Department of orthodontics and Dentofacial Orthopedics, Darshan Dental College and Hospital, Rajasthan, India \\ ${ }^{2}$ Professor and Head, Department of orthodontics and Dentofacial Orthopedics,Darshan Dental College and Hospital, Rajasthan, India
}

Corresponding Author: Dr. Jignesh Keshubhai jigneshkakadiya25190@

gmail.com

Received: $5^{\text {th }}$ May 2016

Accepted: $29^{\text {th }}$ July 2016 Online: $11^{\text {th }}$ September 2016

\begin{abstract}
Background: There is a strong genetic influence in determination of tooth dimensions bearing an influence on the facial dimension. Aims and Objective: To determine a correlation between clinical crown height of upper and lower permanent incisor (11 and 41), molar (16 and 46) and lower facial height clinically and cephalometrically in males and females. Materials \& Methods: A sample of 180 patients were (90 males and 90 females)included in our study, (60-hypodivergent, 60-normodivrgent and 60-hyperdivergent) with an age range of 17-25 years. Threeanthropometric measurements were considered. The lower facial height from subnasale ( $\mathrm{Sn}$ ) to menton, and cephalometric lower facial height distance from anterior nasal spine(ANS) to menton and the clinical crown height of maxillary and mandibular incisors and molars were measured. Observations: Significant difference was observed in relation to 16 in normodivergent patient and lower facial height clinically and cephalometrically in hyperdivergent growth patient. No significant difference between clinical\&cephalometric lower facial height in normodivergent, hypodivergent and hyperdivergent male and female patient. Significant difference was observed between 41 to lower facial height in hypodivergent \& 11,41 \&46 to lower facial height in hyperdivergent patient. Conclusion: A strong significant correlation was observed with clinical crown height of lower central incisor and lower facial height in hyperdivergent and hypodivergent patient.
\end{abstract}

Keywords: Lower facial height, Clinical crown height of incisor \& molar, Lateralcephalogram

\section{INTRODUCTION}

Dental size and shape has been commonly used to learn biological relationships among human populations. ${ }^{1}$ A well balanced attractive face generally indicate a straight profile with equal proportion of upper, middle and lower facial thirds. Profile as well as height of face, helps in diagnosing gross deviation in maxilla-mandibular relationship both Antero-Posteriorly and vertically. ${ }^{2}$

The facial height of young adult subject is regarded a potential determinant in developing the facial harmony and the esthetic. Moreover, they are essential factors in designing the facial type. ${ }^{3}$

The lower facial height is an important component of face. patient with different malocclusions present with varying lower anterior facial heights. ${ }^{4}$ The facial height distance is potentially affected by the more increment or reduction through the compensatory growth pattern of the basoalveolar bone, and the dental eruption. The divergent growth pattern of the facial bones permits the vertical growth of the dentoalveolar components. $^{5}$

Vertical measurements in cephalometric analysis have received 
little attention because of large number of horizontal measurements, and few studies have been devoted directly to facial esthetics that would enable a person to distinguish which dimensions of face and teeth are responsible primarily for a pleasant or an unpleasant face. However the vertical relationships of jaws with the rest of the face have obvious clinical importance in cases of severe open bite and cases of deep bite. ${ }^{6}$

In the cephalometric literature it has become increasingly clear that the cephalometric characteristics of a long or short face structure are predominantly located below the palatal plane. ${ }^{7}$ Vertical growth of the maxilla has much relevant importance and is closely associated with overall facial proportions and together with the growth of the maxillary posterior alveolar process is the primary cause of increase in anterior facial height. $^{8}$

The alveolar structure is a flexible area located between the facial skeleton and occlusal dynamics. Maintaining its growth for many years, this structure tries to establish and maintain occlusal relationships on the basis of changing mandibular and maxillary relationship.

The growth of condyle and alveolar process act as final equalizing factors; and the upper and lower dental and alveolar arches can be considered as a kind of flexible ribbon, adapted to varying jaw relationships and flexible ribbon, adapted to varying jaw relationships and thereby maintaining the normal relationship between dental arches for aesthetics and function.

The proper diagnosis and classification of individual patients is of paramount importance for successful treatment planning in orthodontics. Such a diagnosis includes careful evaluation of the dentofacial complex in the anteroposterior, transverse, and vertical dimensions. Skeletal dysplasia in any dimension typically complicates treatment, and may implicitly warrant or preclude certain treatments.
Malocclusions of a skeletal nature can be especially difficult to treat, and therefore are particularly important to diagnose correctly. ${ }^{10}$ Evaluation of facial proportions and aesthetics should be conducted during clinical examination and the findings should be compared with cephalometric radiographs. ${ }^{11}$

Clinical crown height is a type of dental height which is usually measured to determine the dimension of a tooth. Both clinical crown height and facial height are affected by both genetic and environmental factors. The greater molar height can be influenced by different facial growth types and directions.

The aim of our study was to determine whether a correlation existed between clinical crown height of maxillary and mandibular right permanent incisor, molar and lower facial height clinically and cephalometrically.

\section{MATERIALAND METHODS}

\section{Source of Data}

Study sample consisted of 180 patients reporting to the Department of Orthodontics \& Dentofacial Orthopedics, Darshan Dental College \& Hospital, Udaipur, Rajasthan.

\section{Inclusion Criteria}

1. Patient between 17 to 25 years of age

2. No missing teeth

3. Full complement of teeth till permanent second molar

4. Normal overjet \& overbite \& proportionate upper and lower facial height

5. No history of previous orthodontic therapy

6. No history of trauma or surgery in the dentofacial region

7. No facial asymmetry

8. Angle's class I molar relationship

\section{Exclusion Criteria:}

1. Pre-pubertal patient 
2. Patients associated with some syndrome

3. Patients having any tooth agenesis or supernumeraries, developmental anomalies, traumatic injuries or fractured upper and lower incisors and molars, complex craniofacial deformities or syndromes

Table 1. Sample division into vertical and horizontal facial types using jarabak's ratio

\begin{tabular}{|l|l|l|l|}
\hline Group & Sex & $\begin{array}{l}\text { Jarabak's } \\
\text { ratio (\%) }\end{array}$ & $\begin{array}{l}\text { Total } \\
\text { sample }\end{array}$ \\
\hline Normodivergent & Male & $62-65$ & 30 \\
& Female & $62-65$ & 30 \\
\hline Hyperdivergent & Male & $<62$ & 30 \\
& Female & $<62$ & 30 \\
\hline Hypodivergent & Male & $<65$ & 30 \\
& Female & $<65$ & 30 \\
\hline
\end{tabular}

\section{Study Design:}

A cross sectional study was conducted which included a total of 180 patients, out of which 90 were males and 90 were females ( 60 hypodivergent, 60 normodivrgent and 60 hyperdivergent) (Table 1). A purposive convenience type sampling technique was carried out to select the patients included in the study. Patients included in the study were under the age group ranging from 17 to 25 years. Patients who had undergone any orthodontic treatment and who did not wish to give informed consent were excluded from the study. Informed consent was obtained from all the patients included in the study. The landmarks utilized in the study are enlisted in Table 2. The length of clinical crown was measured by means of a slide gauge with sharpened points for the maxillary central incisor and 1 st molar and mandibular central incisor and 1 st molar. These records were taken on the facial surface of each crown from cusp tip or incisal edge to the deepest curvature of the gingival margin for 11,41 . The measurements on the molar for $16 \& 26$ teeth were made at the mesiobuccal cusp (Figure 1). All the parameters were measured twice at different interval and the average readings were calculated and recorded by two investigators one for clinical crown height and one for lower facial height \& Lateral Cephalogram respectively. The investigators were blinded for their individual measurements respectively. Three anthropometric measurements were measured; one was of soft tissue and two of hard tissues. In soft tissue the lower facial height was measured from soft tissue subnasale to soft tissue menton (Figure 2). In hard tissue the clinical crown height of right central incisors and first permanent molars of upper and lower teeth were measured clinically(Figure 3A-D) \& in cephalometric lower facial height was measured from hard tissue anterior nasal spine to hard tissue menton 12 (Figure 4).

Mean and standard deviation was calculated for all individual parameters, $\mathrm{T}$ test was carried out to determine significance among the samples included for the study with respect to $11,16,41,46$ and lower facial heightclinical \& cephalometric. Correlation coefficient was also determined with $11,16,41$, and 46 to lower facial height.

Table 2: List of Landmarks utilized in the study

\begin{tabular}{|l|l||}
\hline Landmarks & Definition \\
\hline Soft tissue subnasale & $\begin{array}{l}\text { The point at which the columella } \\
\text { merges with the upper lip in the } \\
\text { midsagittal plane. }\end{array}$ \\
\hline Soft tissue menton & $\begin{array}{l}\text { Lowest point on the contour of the soft } \\
\text { tissue chin Found by dropping } \\
\text { perpendicular from the horizontal } \\
\text { plane through skeletal menton. }\end{array}$ \\
\hline $\begin{array}{l}\text { 01Lower facial } \\
\text { height clinical }\end{array}$ & $\begin{array}{l}\text { Millimetric measurement from soft } \\
\text { tissue subnasale to soft tissue menton. }\end{array}$ \\
\hline $\begin{array}{l}\text { Lower facial height } \\
\text { cephalometric }\end{array}$ & $\begin{array}{l}\text { The linear distance from anterior nasal } \\
\text { spine (ANS) to menton. }\end{array}$ \\
\hline $\begin{array}{l}\text { Clinical crown } \\
\text { height }\end{array}$ & $\begin{array}{l}\text { Measurement of crown that can be } \\
\text { seen intraorally. }\end{array}$ \\
\hline
\end{tabular}




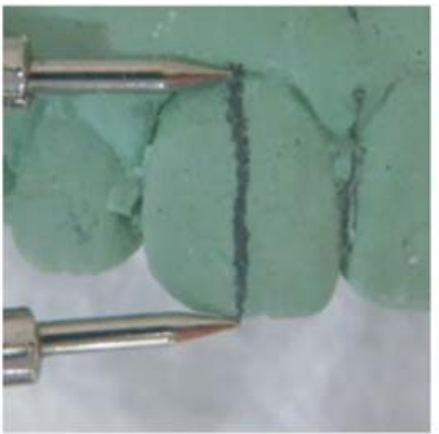

11

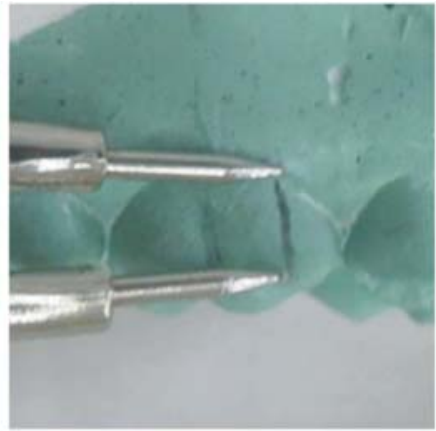

16

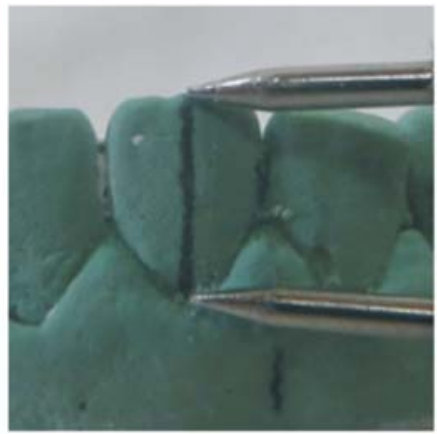

41

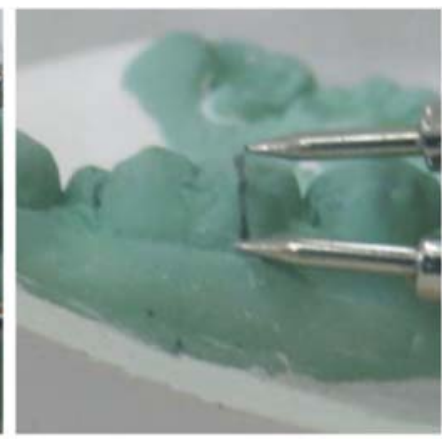

46

Figure 1 : Measurement of Incisor and Molar by Slide gauge

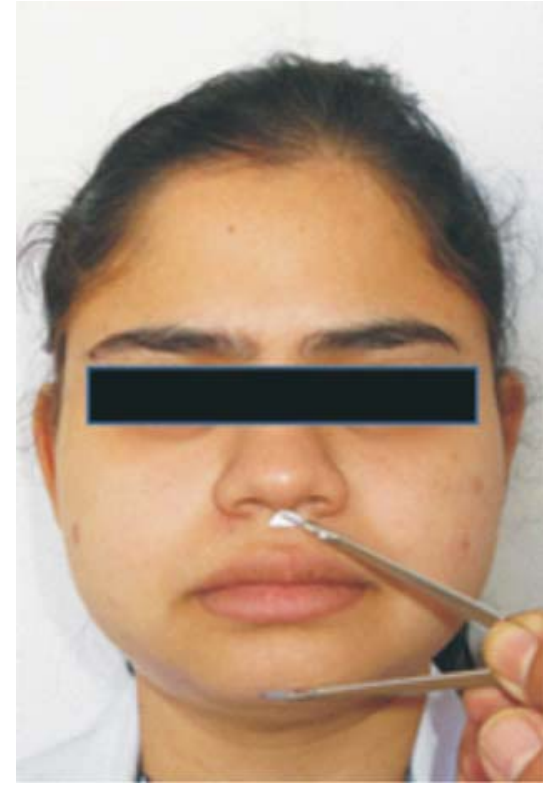

Figure 2: Measurement of Lower Facial Height

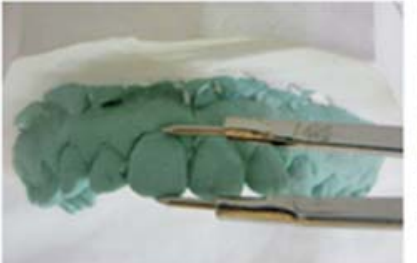

(A)

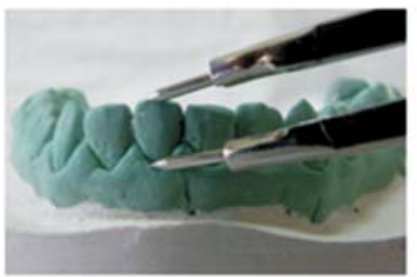

(C)

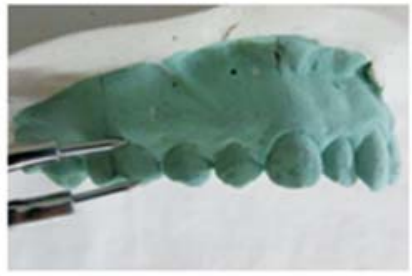

(B)

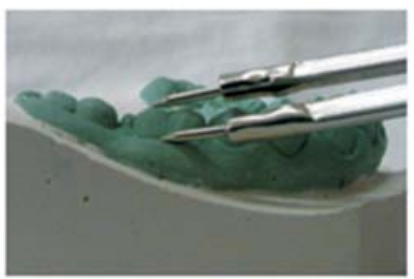

(D)
Figure 3: Measurement of clinical crown height (A-11; B-16; C-41; D-46)

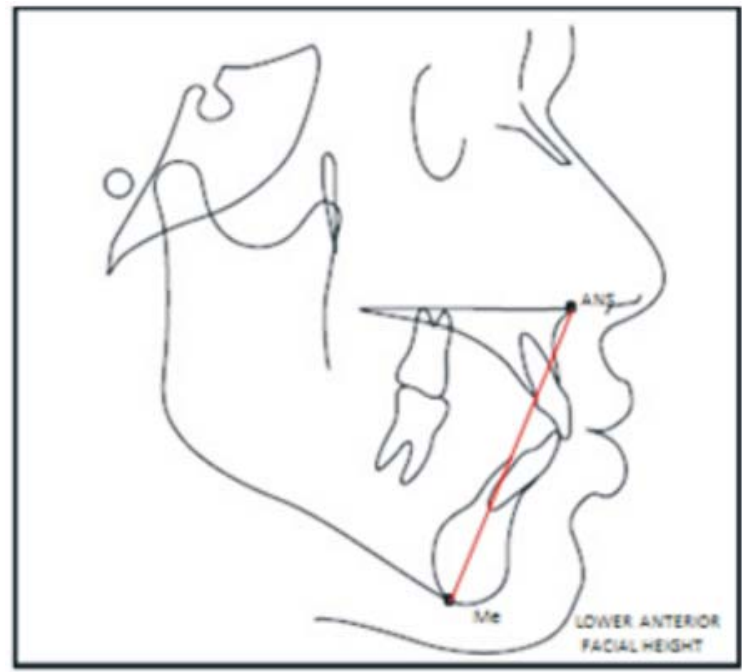

Figure. 4: Measurement of Cephalometric Lower Facial Height

\section{RESULTS}

A mean age of $20.67 \pm 1.34$ and $20.64 \pm 1.34$ years was observed with males and females in hypodivergent, hyperdivergent and normodivergent. A statistically non-significant difference was observed for age in between males and females in hypodivergent, hyperdivergent and normodivergent.

On an overall a mean value of $10.08 \pm 0.89 \mathrm{~mm}$ and $9.92 \pm 1.00 \mathrm{~mm}$ for normodivergent, $10.37 \pm 1.28 \mathrm{~mm}$ and $9.85 \pm 1.01 \mathrm{~mm}$ for hypodivergent \& $10.68 \pm 1.16$ $\mathrm{mm}$ and $10.27 \pm 0.90 \mathrm{~mm}$ for hyperdivergent of clinical crown height of maxillary right central incisor was observed for males and females (Graph 1). 


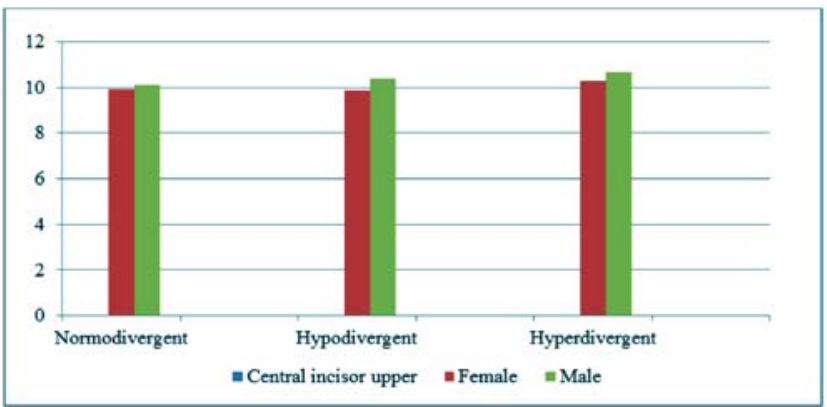

Graph1: Mean and standard deviation of clinical crown height of 11

A mean value of $6.53 \pm 0.54 \mathrm{~mm}$ and $6.02 \pm 0.77 \mathrm{~mm}$ for normodivergent, $6.47 \pm 0.90 \mathrm{~mm}$ and $6.12 \pm 0.67 \mathrm{~mm}$ for hypodivergent \& $6.63 \pm 0.82 \mathrm{~mm}$ and $6.47 \pm 0.88 \mathrm{~mm}$ for hyperdivergent of clinical crown height of maxillary right permanent molar was observed for males and females (Graph 2).

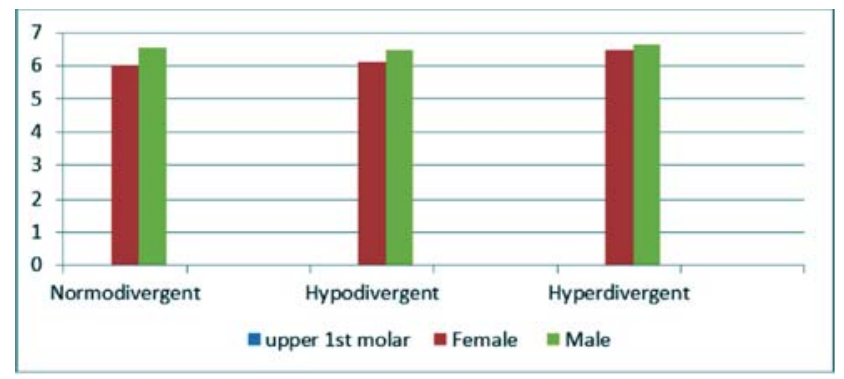

Graph 2: Mean and standard deviation of clinical crown height of 16 .

Clinical crown height of right lower incisor revealed a mean value of $8.14 \pm 1.18 \mathrm{~mm}$ and $8.45 \pm 1.09 \mathrm{~mm}$ for normodivergent, $8.40 \pm 0.98 \mathrm{~mm}$ and $8.11 \pm 1.22 \mathrm{~mm}$ for hypodivergent \& $8.63 \pm 1.29 \mathrm{~mm}$ and $8.80 \pm 1.13 \mathrm{~mm}$ for hyperdivergent for males and females (Graph 3 ).

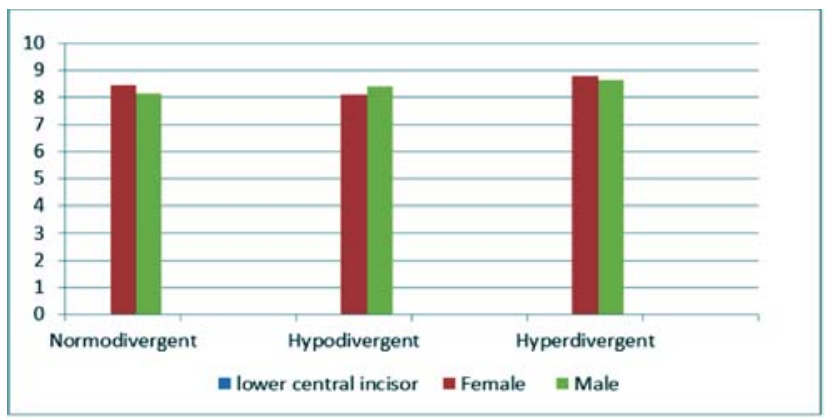

Graph 3: Mean and standard deviation of clinical crown height of 41
A mean value of $6.35 \pm 0.77 \mathrm{~mm}$ and $6.37 \pm 0.57 \mathrm{~mm}$ for normodivergent, $6.53 \pm 0.61 \mathrm{~mm}$ and $6.45 \pm 0.76 \mathrm{~mm}$ for hypodivergent\& $6.68 \pm 0.90 \mathrm{~mm}$ and $6.58 \pm 0.62 \mathrm{~mm}$ for hyperdivergent of clinical crown height of right

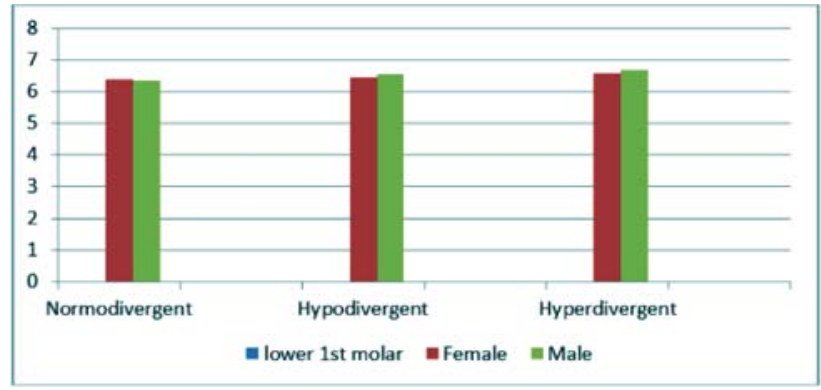

Graph 4: Mean and standard deviation of clinical crown height of 46

lower permanent molar was observed for males and females (Graph 4).

Lower facial height had a mean value of $68.18 \pm 4.83$ $\mathrm{mm}$ and $66.63 \pm 5.29 \mathrm{~mm}$ for normodivergent, $66.93 \pm 5.07 \mathrm{~mm}$ and $66.40 \pm 3.21 \mathrm{~mm}$ for hypodivergent \& $76.73 \pm 5.47 \mathrm{~mm}$ and $71.30 \pm 5.75 \mathrm{~mm}$ for hyperdivergent for males and females respectively (Graph 5).

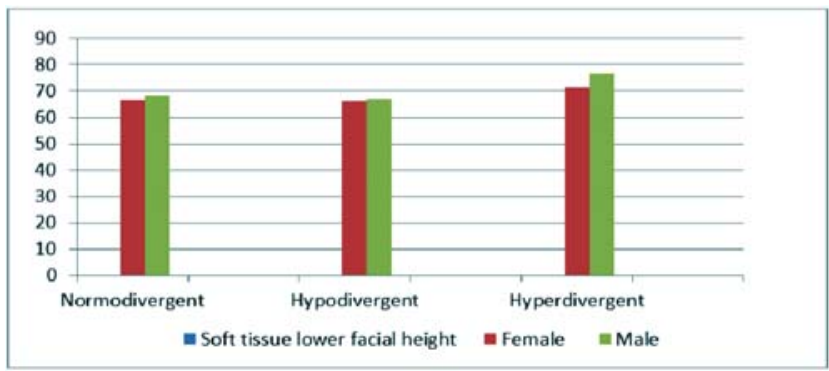

Graph 5: Mean and standard deviation of Soft tissue Lower facial height $(\mathrm{mm})$

Cephalometric Lower facial height had a mean value of $69.73 \pm 4.81 \mathrm{~mm}$ and $67.53 \pm 5.93 \mathrm{~mm}$ for normodivergent, $67.67 \pm 5.47 \mathrm{~mm}$ and $67.13 \pm 3.22 \mathrm{~mm}$ for hypodivergent\& $77.93 \pm 5.67 \mathrm{~mm}$ and $72.97 \pm 6.31$ $\mathrm{mm}$ for hyperdivergentfor males and females respectively (Graph 6).

On Statistical analysis, high significance was observed for 16 in normodivergent and lower facial height 


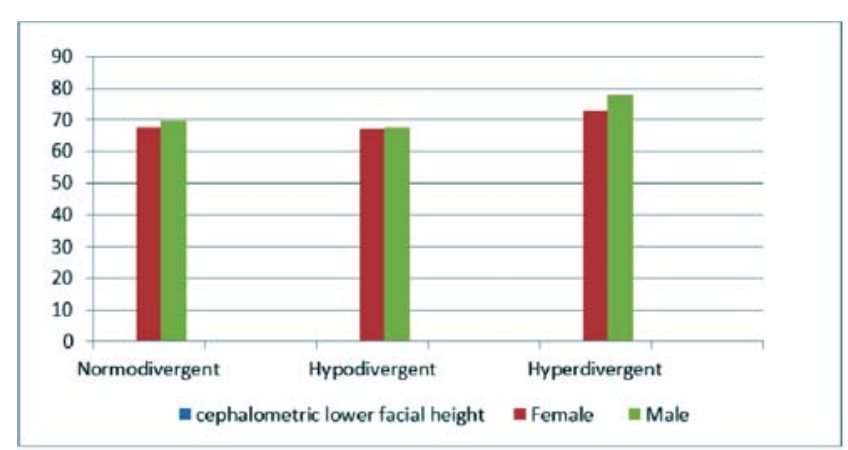

Graph.6: Mean and standard deviation of cephalometrically Lower facial height(mm)

clinically and cephalometrically in Hyperdivergent (Table 3).

Table 3: T test 11,16,41,46,clinical lower facial height and cephalometric lower facial height

\begin{tabular}{|l|c|c|c|c|c|c|}
\hline & \multicolumn{2}{|c|}{$\begin{array}{c}\text { Normo- } \\
\text { divergent }\end{array}$} & \multicolumn{2}{c|}{$\begin{array}{c}\text { Hypo- } \\
\text { divergentl }\end{array}$} & \multicolumn{2}{c|}{$\begin{array}{c}\text { Hyper- } \\
\text { divergent }\end{array}$} \\
\hline & $\begin{array}{c}\mathrm{t} \text { - } \\
\text { value }\end{array}$ & P value & $\begin{array}{c}\mathrm{t}- \\
\text { value }\end{array}$ & $\begin{array}{c}\mathrm{P} \\
\text { value }\end{array}$ & $\begin{array}{c}\mathrm{t}- \\
\text { value }\end{array}$ & P value \\
\hline 11 & 0.68 & 0.498 & 1.74 & 0.088 & 1.56 & 0.124 \\
\hline 41 & -1.06 & 0.295 & 1.00 & 0.320 & -0.53 & 0.596 \\
\hline 16 & 3.01 & $0.004 * *$ & 1.71 & 0.092 & 0.76 & 0.451 \\
\hline 46 & -0.10 & 0.924 & 0.47 & 0.642 & 0.50 & 0.619 \\
\hline $\begin{array}{l}\text { Clinical lower } \\
\text { facial height }\end{array}$ & 1.03 & 0.306 & 0.49 & 0.628 & 3.75 & $0.000 * *$ \\
\hline $\begin{array}{l}\text { Cephalometric } \\
\text { lower facial } \\
\text { height }\end{array}$ & 1.58 & 0.120 & 0.46 & 0.647 & 3.21 & $0.002 * *$ \\
\hline
\end{tabular}

$\mathrm{P}>0.05(\mathrm{NS}) ; \mathrm{P}<0.05$ (S); $\mathrm{P}<0.01(\mathrm{HS})$

Notstatistically significant was observed on comparison between clinical lower facial and cephalometric lower facial height in male and female (Table 4).

Table 4: comparison between clinical lower facial height and cephalometric lower facial height in male and female

\begin{tabular}{|l|c|c|c|c|}
\hline Clinically and & \multicolumn{2}{|c|}{ Female } & \multicolumn{2}{c|}{ Male } \\
\cline { 2 - 5 } $\begin{array}{l}\text { cephalometrically } \\
\text { lower facial height }\end{array}$ & t- value & $\mathrm{p}$-value & t- value & $\mathrm{p}$-value \\
\hline Normodivergent & 0.48 & 0.631 & 1.25 & 0.218 \\
\hline Hypodivergent & 0.88 & 0.381 & 0.54 & 0.592 \\
\hline Hyperdivergent & 1.07 & 0.289 & 0.83 & 0.408 \\
\hline Total & 1.23 & 0.219 & 1.14 & 0.254 \\
\hline
\end{tabular}

$\mathrm{P}>0.05$ (NS); $\mathrm{P}<0.05$ (S); $\mathrm{P}<0.01$ (HS)
In males correlation coefficient was determined of $11,16,41$, and 46 to soft tissue lower facial height. In hypodivergent patient 41 is highly statistically significant with respect to lower facial height. In hyperdivergent patient $11 \& 41$ is statistically significant and 46 highly statistically significant with respect to lower facial height (Table 5).

Table 5: Correlation coefficient ( $\mathrm{p}$-value) soft tissue lower facial height for male

\begin{tabular}{|l|c|c|c|}
\hline & $\begin{array}{c}\text { Normo } \\
\text { divergent }\end{array}$ & $\begin{array}{c}\text { Hypo } \\
\text { divergent }\end{array}$ & $\begin{array}{c}\text { Hyper } \\
\text { divergent }\end{array}$ \\
\hline $\begin{array}{l}\text { Tooth } \\
\text { no. }\end{array}$ & $\begin{array}{c}\text { Lower facial } \\
\text { height }\end{array}$ & $\begin{array}{c}\text { Lower facial } \\
\text { height }\end{array}$ & $\begin{array}{c}\text { Lower facial } \\
\text { height }\end{array}$ \\
\hline 11 & $-0.004(0.985)$ & $0.283(0.130)$ & $0.373(0.042)^{*}$ \\
\hline 16 & $0.193(0.308)$ & $0.283(0.130)$ & $0.220(0.243)$ \\
\hline 41 & $0.080(0.672)$ & $\begin{array}{c}0.534 \\
(0.002)^{* *}\end{array}$ & $0.380(0.038)^{*}$ \\
\hline 46 & $0.136(0.475)$ & $0.150(0.429)$ & $0.480(0.007)^{* *}$ \\
\hline
\end{tabular}

$\mathrm{P}>0.05$ (NS); $\mathrm{P}<0.05$ (S); $\mathrm{P}<0.01$ (HS)

In females correlation coefficient was determined of $11,16,41$, and 46 to soft tissue lower facial height. In hypodivergent \& hyperdivergent patient 41 is statistically significant with respect to lower facial height (Table 6).

Table 6: Correlation coefficient ( $p$-value) soft tissue lower facial height for female

\begin{tabular}{|l|c|c|c|}
\hline & $\begin{array}{c}\text { Normo } \\
\text { divergent }\end{array}$ & $\begin{array}{c}\text { Hypo } \\
\text { divergent }\end{array}$ & $\begin{array}{c}\text { Hyper } \\
\text { divergent }\end{array}$ \\
\hline $\begin{array}{l}\text { Tooth } \\
\text { no. }\end{array}$ & $\begin{array}{c}\text { Lower facial } \\
\text { height }\end{array}$ & $\begin{array}{c}\text { Lower facial } \\
\text { height }\end{array}$ & $\begin{array}{c}\text { Lower facial } \\
\text { height }\end{array}$ \\
\hline 11 & $0.092(0.629)$ & $0.115(0.546)$ & $0.098(0.608)$ \\
\hline 16 & $0.090(0.638)$ & $0.018(0.926)$ & $0.057(0.767)$ \\
\hline 41 & $-0.231(0.219)$ & $0.433(0.017)^{*}$ & $0.393(0.032)^{*}$ \\
\hline 46 & $0.044(0.818)$ & $-0.048(0.801)$ & $0.202(0.285)$ \\
\hline
\end{tabular}

$\mathrm{P}>0.05$ (NS); $\mathrm{P}<0.05$ (S); $\mathrm{P}<0.01$ (HS)

When comparison of correlation coefficient between lower facial height of11,16,41 and 46 to males and females was done, in hypodivergent patient 41 was seen to be statistically highly significant \& in hyperdivergent patient $11 \& 41$ were statistically significant \& 46 statistical highly significant (Table 7). 
Vol. 4 (II) 2016 Dental Journal of Advance Studies

Table 7: Comparison of correlation coefficient ( p-value) soft tissue lower facial height for male and female

\begin{tabular}{|l|c|c|c|c|c|c|c|c|c|}
\hline & \multicolumn{3}{|c|}{ Normodivergent } & \multicolumn{3}{c|}{ Hypodivergent } & \multicolumn{3}{c|}{ Hyperdivergent } \\
\hline \multirow{2}{*}{ Tooth no. } & \multicolumn{3}{|c|}{ Lower facial height } & \multicolumn{3}{c|}{ Lower facial height } & \multicolumn{3}{c|}{ Lower facial height } \\
\cline { 2 - 11 } & male & Female & P value & male & female & P value & Male & Female & P vale \\
\hline 11 & -0.004 & 0.092 & 0.647 & 0.283 & 0.115 & 0.072 & 0.373 & 0.098 & $0.018^{*}$ \\
\hline 16 & 0.193 & 0.090 & 0.200 & 0.283 & 0.018 & 0.113 & 0.220 & 0.057 & 0.214 \\
\hline 41 & 0.080 & -0.231 & 0.478 & 0.534 & 0.433 & $0.000^{* *}$ & 0.380 & 0.393 & $0.015^{*}$ \\
\hline 46 & 0.136 & 0.044 & 0.493 & 0.150 & -0.048 & 0.630 & 0.480 & 0.202 & $0.007^{* *}$ \\
\hline
\end{tabular}

$\mathrm{P}>0.05$ (NS); $\mathrm{P}<0.05$ (S); $\mathrm{P}<0.01$ (HS)

\section{DISCUSSION}

A perfect smile is an important component of esthetics andthis goes beyond having white and straight teeth. Vertical proportions of both face and dentition play a significant role to determine the facial attractiveness and identity of an individual. ${ }^{1}$ The proportion of facial structures and the relationship between facial measurements and natural teeth is used as a guide to achieve facial harmony and esthetics for an individual. ${ }^{2}$ Orthodontically when a patient is visualized for the treatment; macro-esthetics, miniesthetics and micro-esthetic measurements are taken into consideration. ${ }^{14,15}$

All the parameters i.e. macro, mini and microesthetics are considered while planning an orthodontic treatment and smile designing. Hence the lower facial height and the clinical crown height of incisor play a significant role in determining an orthodontic treatment planning and the smile makeover of a patient. ${ }^{1}$

Literature also suggests that clinical crown height and lower facial height gets affected in patients who have undergone orthodontic treatment. When age of samples included in the study was compared for males and females a statistical non significance was observed. Probable cause for such an observation could be attributed to the study design, in which the samples included in the study had an age range of 17-25 years.

On an overall the clinical crown height of 11,16 , clinically lower facial height and cephalometric lower facial height were both clinically and statistically larger in males in comparison to females in Normodivergent, hyperdivergent and hypodivergent patient. The clinical crown height 41,46 in hypodivergent patient \& clinical crown height 46 in hyperdivergent patient were both clinically and statistically larger in male in comparison to female. (Table 2). By Zarana Purohit the clinical crown height of 16, 41, 46 and lower facial height were both clinically and statistically larger in males in comparison to females. ${ }^{1}$ Our observations correlated with observations made by Morley J, Eubank J. However, the clinical crown height of 11 was found to besmaller in males in comparison to females.

T test was carried out to determine significance among the samples included for the study with respect to $11,16,41,46$ and clinically \& cephalometrically lower facial height. Statistical significance was observed in 16 in normodivergent and clinically \& cephalometric lower facial height in hyperdivergent as observed in table 3. By Zarana Purohit Statistical significance was observed among all the parameters except for 16 and 41 and lower facial height.

The lower facial height is influenced by both maxillary and mandibular jaws. Movable mandibular jaw could be attributed for such an observation. The lower third of face is further divided into upper $1 / 3 \mathrm{rd}$ and lower $2 / 3$ rd a further study has to be conducted to find out a correlation of the clinical crown height and lower facial thirds.

No Statistical significance was observed in clinically and cephalometric lower facial height in 
normodivergent, hypodivergent \& hyperdivergent (Table 4).

When correlation coefficient was determined in males with 11, 16, 41, and 46 to lower facial height a strong statistical significant correlation was observed with 41 to lower facial height in hypodivergent \& 11, 41 $\& 46$ to lower facial height in hyperdivergent (Table 5). In females a strong correlation coefficient was observed with 41 to lower facial height. This observation revealed that 41 had significant correlation both clinically and statistically in hypodivergent and hyperdivergent patient (Table 4).

We found that 41 contributed more proportionally to lower facial height than the maxillary dental height. The proportionally dental heights in hypodivergent types showed no significant except 41 differences from the proportional dental heights in normodivergent patients. The hyperdivergent patient, however, recorded significant differences of except 16 of all of their proportional dental heights when compared to normodivergent patient (Table 7) by R J Parlow The proportionally dental heights in hypodivergent types showed no significant differences from the proportional dental heights in normal patients. The hyperdivergent patient significant differences of all of their proportional dental heights when compared to normodivergent patient. ${ }^{15}$ When linear measurements were substituted for the proportional dental heights in each vertical classification, it was seen that in hypodivergent patients all the teeth were infra-erupted. The anterior dental height in hypodivergent patients decreased approximately twice as much as the posterior dental height. When substitution of linear measurements was accomplished in the hyperdivergent patterns, all the teeth appeared supra-erupted. The anterior dental height in hyperdivergent patients increased approximately twice as much as the posterior dental height. In hypodivergent and hyperdivergent skeletal dysplasias, the anterior teeth were infraerupted and supraerupted, respectively, more than the posterior teeth. The showed significant increases as the vertical height increased.

The overbite was shown to increase significantly over normal patterns in hypodivergent patterns and to decrease significantly in hyperdivergent patterns. There were no correlations between proportional dental heights and overbite in any of the vertical classifications. Relatively few correlations between proportional dental heights were recorded for the skeletal dysplasias other than the teeth proportioned with each other. The hyperdivergent vertical patterns showed correlations between all proportional dental heights except 16. No correlations existed between dental height and amount of discrepancy present.

When comparison of correlation coefficient between lower facial height of 11, 16, 41, and 46 to males and females was done in hypodivergent patient lower central incisor \& in hyperdivergent patient clinical central upper incisor, central lower incisor and molar revealed statistical significance. 11, 41 and 46 revealed significance at $99 \%$ confidence interval in hyperdivergent (Table 7).

\section{CONCLUSION}

On an overall statistically and clinically, male had a larger height of both clinical crown height and lower facial height clinically and cephalometric in hypodivergent, normodivergent and hyperdivergent patient except 41 in hyperdivergent and normodivergent. Clinical crown height of 11, 41, 46 had significant positive correlation with lower facial height in hyperdivergent patient. And 41 had significant positive correlation with lower facial height in hypodivergent patient. A further study has to be conducted to find out a correlation of the clinical crown height and lower facial thirds.

\section{REFERENCES}

1. Zarana Purohit, Santosh Kumar Goje, Narayan Kulkarni, Purvesh Shah, Kartik Patel, Nilixa Dave. Is clinical crown height a marker of lower anterior facial height??? Journal of Dentistry and Oral Biosciences Vol. 2012;3(2):13-18. 
2. Abdel-Kader HM. Clinical crown length and reduction in overjet, overbite, and dental height with orthodontic treatment. Am. J. Orthod. 1986; 89 (3):246-50.

3. Hussain A Obaidi. Variation of facial heights among the Class I, II and III dentoskeletal relationships ( Cephalometric study). Al-Rafidain Dent J. 2006; 6(2): 98-105.

4. Alka Singh, Vijay P. Sharma, Pradeep Tandon A Cephalometric Evaluation of Lower Face Height and Its Relationship with Dentoalveolar Vertical Dimensions. J Ind Orthod Soc 2006; 39; 204-212.

5. Canonn J. Craniofacial height and depth increments in normal children. Angle Orthod. 1970; 40: 202-218.

6. AM Deoghare, Pankaj Akhare, Rohit Patil, Amanish Singh Shinh. Comparison of Incisor Molar and Anterior Facial Height in Normal Angle Class II Division 1 and Class III Malocclusion: A Cephalometric Study. J Ind Orthod Soc 2012;46(4):304-307.

7. Issacson JR. Extreme variation in vertical facial growth and associated variation in skeletal and dental relations. Angle Orthod Vol. 1971; 41(3): 219-29

8. Schudy FF. The control of vertical overbite in clinical orthodontics. Angle Orthodontics 1968; Vol. 38(1): 19-39.

9. Solow B. The dentoalveolar compensatory mechanism: background and clinical implications. Br J Orthod 1980; 7 : 145-161.

10. Al-Zubaidi SA, Obaidi HA. The variation of the lower anterior facial height and its component parameters among the three over bite relationships (Cephalometric study). Al-Rafidain Dent J. 2006; 6(2): 106-113.

11. Profit. Wr. Orthodontia Contemporanea 2nd ed. Rio-de Janeiro. Guanabara Koogan 1995.

12. Márcia Cristina Cunha Costa, Marcelo de Castellucci e Barbosa, Marcos Alan Vieira Bittencourt. Evaluation of facial proportions in the vertical plane to investigate the relationship between skeletal and soft tissue dimensions. Dental Press J Orthod 2011; 16(1):99-106.

13. Sterrett JD, Oliver T, Robinson F, Fortson W, Knaak B, Russell CM. Width/length ratios of normal clinical crowns of the maxillary anterior dentition in man. J Clin Periodontol. 1999; 26(3):153-7.

14. R.J.Parlow. A radiographic cephalometric appraisal of the proportional relationship of the molar and incisor heights in hypodivergent, hyperdivergent, and normal patients. Am.J.Orthod. 1972; 61(3) 309-310.

15. Profitt WR, Fields HW, Sarver DM. contemporary orthodontics. Elsevier 4th ed. Noida UP India pg 309-316.

Source of Support: Nil, Conflict of Interest: None Declared 